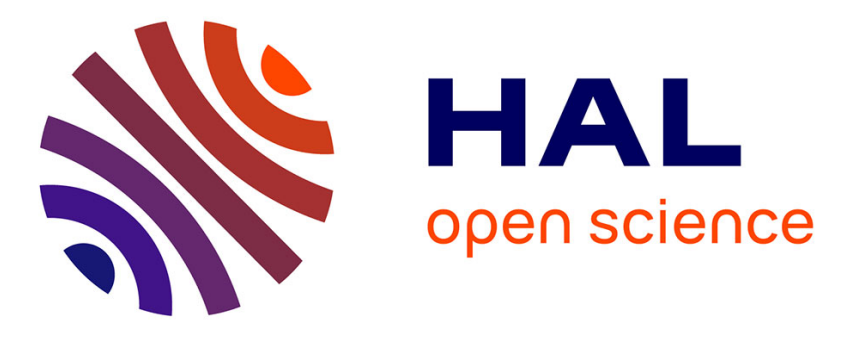

\title{
Reduced physical aging rates of polylactide in polystyrene/polylactide multilayer films from fast scanning calorimetry
}

Xavier Monnier, Samira Fernandes Nassar, Sandra Domenek, Alain Guinault, Cyrille Sollogoub, Eric Dargent, Nicolas Delpouve

\section{To cite this version:}

Xavier Monnier, Samira Fernandes Nassar, Sandra Domenek, Alain Guinault, Cyrille Sollogoub, et al.. Reduced physical aging rates of polylactide in polystyrene/polylactide multilayer films from fast scanning calorimetry. Polymer, 2018, 150 (15), pp.1-9. 10.1016/j.polymer.2018.07.017 . hal-01912592

\section{HAL Id: hal-01912592 https://hal.science/hal-01912592}

Submitted on 5 Nov 2018

HAL is a multi-disciplinary open access archive for the deposit and dissemination of scientific research documents, whether they are published or not. The documents may come from teaching and research institutions in France or abroad, or from public or private research centers.
L'archive ouverte pluridisciplinaire HAL, est destinée au dépôt et à la diffusion de documents scientifiques de niveau recherche, publiés ou non, émanant des établissements d'enseignement et de recherche français ou étrangers, des laboratoires publics ou privés. 


\title{
Reduced physical aging rates of polylactide in polystyrene/polylactide multilayer films from fast scanning calorimetry
}

\author{
Xavier Monnier ${ }^{\mathrm{a}, 1}$, Samira Fernandes Nassar ${ }^{\mathrm{b}}$, Sandra Domenek ${ }^{\mathrm{b}}$, Alain Guinault ${ }^{\mathrm{c}}$, \\ Cyrille Sollogoub ${ }^{c}$, Eric Dargent ${ }^{\mathrm{a}}$, Nicolas Delpouve ${ }^{\mathrm{a}, *}$ \\ a Normandie Univ, UNIROUEN Normandie, INSA Rouen, CNRS, Groupe de Physique des Matériaux, 76000 Rouen, France \\ ${ }^{\mathrm{b}}$ UMR Ingénierie Procédés Aliments, AgroParisTech, INRA, Université Paris-Saclay, 1 Avenue des Olympiades, F-91300 Massy, France \\ ${ }^{\mathrm{c}}$ PIMM, Arts et Métiers ParisTech, CNRS, CNAM, 151 Bd de l'Hôpital, F-75013 Paris Cedex, France
}

Keywords:

Confinement

Structural relaxation

Glass transition

\begin{abstract}
A B S T R A C T
The physical aging behavior of amorphous polylactide constrained against polystyrene in layers of $300 \mathrm{~nm}$, thanks to the layer-multiplying co-extrusion process, was investigated by fast-scanning calorimetry (FSC). By cooling down the sample from the liquid state to the glassy one at very fast scanning rates, it was possible to investigate the structural relaxation of the polymer glass at high temperatures for which the time needed to reach the equilibrium was shortened. Therefore it was possible to perform the study of physical aging in experimental conditions providing an expanded view of the structural relaxation for short aging times. Taking benefit of this property, it was highlighted that the aging kinetics of polylactide occurred significantly slower in the multilayer film, in comparison with a bulk amorphous film. The process of recovery in the multilayer system was found to occur at similar rates, or even slower, than in a three-layer film in which polylactide reached its maximum extent of crystallinity. This was attributed to mobility hindrance that might be inherent to the extrusion conditions or associated with the presence of capped interfaces with polystyrene.
\end{abstract}

\section{Introduction}

The environmental concern has increased the interest in the development of biodegradable packaging materials to replace petroleum-based plastic packaging. Polylactide (PLA) is easy to process, and has interesting use properties such as high transparency and gloss, and high tensile modulus. Several studies showed the potential of PLA in the packaging sector [1,2] although its brittleness is a limiting factor and its barrier properties need improvement [3]. Thermal crystallization can contribute to increase barrier properties, under the condition to limit the formation of a dedensified rigid amorphous fraction (RAF) during annealing [4,5]. The potential of layer multiplying co-extrusion to improve barrier properties has emerged recently [6-9]. This process combines two

\footnotetext{
* Corresponding author. Normandie Univ, UNIROUEN Normandie, INSA Rouen, CNRS, Groupe de Physique des Matériaux, 76000, Rouen, France.

E-mail address: nicolas.delpouve1@univ-rouen.fr (N. Delpouve)

1 Present address: Centro de Física de Materiales (CSIC-UPV/EHU) \& Donostia International Physics Center (DIPC), Paseo Manuel de Lardizábal 4, 20018 San Sebastián, Spain.
}

or three polymers into a continuous alternating layered structure with hundreds or thousands of layers, offering the possibility to decrease the individual layer thickness down to several nanometers, which yields confinement of one polymer by the other. This technique offers moreover the huge advantage of being able to produce objects at large scale and to be transferable to the industry for the fabrication of commodity materials. It has recently been shown with this technique that the crystallization of PLA under confinement can delay the formation of the RAF and therefore open new ways for property optimization [10].

PLA has a glass transition temperature $\left(T_{g}\right)$ of approximately $60^{\circ} \mathrm{C}$ and is therefore sensitive to physical aging at room temperature (i.e. storage below but near $T_{g}$ ), which can impact negatively its dimensional stability during service. Physical aging is caused by structural relaxation towards equilibrium and characterized by a decrease in thermodynamic quantities, such as specific volume, enthalpy and entropy [11-15]. It generally exacerbates the inherent brittleness of PLA [16] and increases its gas permeability [17].

Various methods have been used to study physical aging, including differential scanning calorimetry (DSC) [18,19], gas permeability measurement [20,21], dielectric spectroscopy 
[22-24], ellipsometry [25], or positron annihilation spectroscopy [26]. In DSC, physical aging is characterized by the enthalpy relaxation, which appears as the development of an endothermic peak superimposed to the heat capacity step of the glass transition. Recently, the development of fast scanning calorimetry (FSC) has received much interest regarding physical aging [27-29]. This technique allows heating up and cooling down polymers as fast as thousand Kelvin per second. This performance requires a drastically reduced sample mass (typically tens to hundreds ng) to diminish the thermal lag (i.e., temperature gradients occurring in sample and instrument during the measurement). The major advantage of the very high cooling rates is that FSC can provide glasses with high level of enthalpy or specific volume. Physical aging can also be investigated at temperatures higher than in standard DSC conditions. Since the time to reach equilibrium depends only on the aging temperature $T_{a g}$ [30], this allows reaching the thermodynamic equilibrium much faster [31,32].

Two main factors are expected to govern molecular dynamics, and in particular physical aging, in multi-nanolayers films: the reducing of the domain accessible for relaxation which can be considered as a pure geometric confinement effect, and the nature of the interface between the layers. How physical aging occurs when the polymer dimension is reduced at the nanoscale is under debate, because conflicting results have been recently reported, meaning acceleration [33-39], slowing down [40,41], or invariance [25] of the physical aging rate. Therefore several parameters, with possibly antagonist effects, should be considered when investigating the structural relaxation in confined landscapes, such as confinement type, aging conditions, and interfacial interactions [42]. For example differences in physical aging kinetics were reported for free-standing thin films and multi-nanolayers films. Murphy et al. [21] reported that polysulfone aged slower in multilayer films compared to free-standing thin films. Boucher et al. reported accelerated aging with decreasing the thickness of thin free-standing PS films [43], whereas Langhe et al. [44] observed a reduced aging rate of thin PS layers in multi-nanolayer films of PS and polycarbonate (PC). In this context the objective of the present work is to contribute to the discussion about the impact of the interface effects in multi nanolayers films on the physical aging kinetics. We showed recently the possibility to use the layer-multiplying coextrusion process for the confinement of thin PLA layers (20 nm thickness) between PS [10]. No interphase was evidenced in PS/PLLA films [10], which allows here investigating the physical aging process of constrained PLA between slippery walls. We introduce furthermore amorphous and semi-crystalline samples to scale the aging rate in PS/PLLA films by comparing it with the aging rate in two different landscapes: an unconstrained amorphous phase and a constrained intra-lamellar amorphous phase with incomplete decoupling between amorphous and crystalline phases [45].

\section{Experimental}

\subsection{Material processing}

Polylactide (PLA) pellets were purchased from Corbion Purac

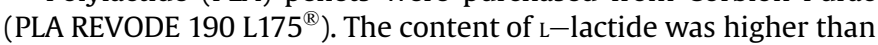
99\%. Polystyrene (PS) pellets were obtained from Total Petrochemicals (PS Lacqrene 1340). Due to the sensitivity of polylactide to hydrolytic degradation, PLA pellets were dried before extrusion in a Somos ${ }^{\circledR}$ dryer while the residual humidity level was checked with an Aboni ${ }^{\circledR}$ FMXTM humidity tracer. Pellets were dried at $80^{\circ} \mathrm{C}$ during $12 \mathrm{~h}$ to reach a humidity level between 250 and $300 \mathrm{ppm}$. After drying, PLA pellets were subsequently extruded by single screw extrusion with a $30 \mathrm{~mm}$ diameter extruder (with a $33 \mathrm{~L} / \mathrm{D}$ (length on diameter) barrel) and a classical three sections screw. The extruder screw speed was set to $40 \mathrm{rpm}$. A mixer device containing 4 Sulzer SMX ${ }^{\mathbb{R}}$ mixers was placed between the barrel and the die to ensure a better homogenization of the melt. A flat die of $200 \mathrm{~mm}$ width and a chill roll equipment were used to manufacture films of approximately $300 \mu \mathrm{m}$ thickness. The temperature profile of the barrel for the six zones was $180-180-180-185-190-190{ }^{\circ} \mathrm{C}$. The temperatures of the mixer device and the die were defined at $200{ }^{\circ} \mathrm{C}$. The roll temperature was fixed at $20^{\circ} \mathrm{C}$ to cool down the films. The resulting films are amorphous according to X-Ray diffraction and Differential Scanning Calorimetry (not shown there) and are called amorphous systems (AS) in the paper (see Table 1). A layer multiplying co-extrusion process was used to fabricate films of alternating layers of PLA and PS. The process is presented in Fig. 1. It consists in two single screw extruders of $20 \mathrm{~mm}$ diameter with gear pumps to regulate the composition, a three-layer feed block (A-B-A), a series of layer-multiplying elements, a flat die of $200 \mathrm{~mm}$ and chill rolls at $20^{\circ} \mathrm{C}$. PLA was extruded to form the central layer of the films initial structure and PS the external layers. The extrusion conditions are given in Table 2.

The composition of the PLA/PS films was fixed at 25/75 (w/w). The initial three-layer polymer flow entered a mixing section, followed by a sequence of layer-multiplying elements. The melt was initially cut in half vertically, and then both flows were superposed, compressed and stretched to its original width, hence doubling the number of layers with each layer-multiplying element. A series of $n$ elements leads thus to $2^{n+1}+1$ alternating layers. Using eight multiplying elements, a multilayer system (MS) of $300 \mu \mathrm{m}$ in thickness with 513 alternating layers of PLA and PS was created. Atomic Force Microscopy (AFM) images showed that the integrity of both PS and PLA layers was respected as they were continuous and relatively uniform (Figure SI.1 in Supplementary Information). When no multiplying elements are added on the line, the three-layer film is collected as is and referred as amorphous 3-layer system (A3S). Its thickness was fixed at $120 \mu \mathrm{m}$. Post-processing crystallization was carried out by annealing $\boldsymbol{A} 3 \boldsymbol{S}$ at $85^{\circ} \mathrm{C}$ for $180 \mathrm{~min}$ to form crystallized 3-layer systems (C3S). For the annealing treatment, the films were sandwiched between two sheets of Teflon and two stainless steel plates, and then thermo-compressed using a heat press (Darragon, France) at a pressure set to $5.10^{6} \mathrm{~Pa}$. The micrograph of the $\mathbf{C 3 S}$ (Figure SI.1 in Supplementary Information) obtained from polarizing optical microscopy (POM) showed that the crystallization generates mostly small size spherulites with diameter less than $20 \mu \mathrm{m}$. According to Modulated Temperature Differential Scanning Calorimetry (MT-DSC) analyses, the crystallinity degree of the $\mathbf{C 3 S}$ was about $35 \%$ and an important amount of rigid amorphous fraction, close to $40 \%$, was generated. Details regarding MT-DSC protocols are given in Supplementary Information in Figure SI.2.

\subsection{Fast scanning calorimetry (FSC)}

The fast scanning calorimetry (FSC) analyses were performed using a power compensation twin-type chip-based fast scanning calorimeter Flash DSC 1 (Mettler Toledo) equipped with a Huber TC100 intra-cooler. The samples were placed on the sensitive area of a MultiSTAR UFS 1 MEMS chip sensor (Fig. 2A). Prior to use, the chip was conditioned and corrected according to Mettler Toledo procedures. A thin layer of silicone oil was used to promote adhesion of the sample onto the chip and to improve thermal contact. Samples were continuously flushed with a $20 \mathrm{~mL} \mathrm{~min}^{-1}$ flow of gaseous nitrogen to prevent condensation from environmental moisture and to ensure temperature control. Sample mass was estimated from the step change in heat flow at the glass transition by assuming that the heat capacity value step $\triangle C p$ obtained by FSC 
Table 1

Processing characteristics and microstructure parameters of monolayer, 3-layer, and multilayer films.

\begin{tabular}{|c|c|c|c|c|c|c|c|c|c|c|}
\hline Acronym & Film & Processing method & $\begin{array}{l}\text { PLA/PS } \\
\text { composition (w/ } \\
\mathrm{w})\end{array}$ & $\begin{array}{l}\text { Number of } \\
\text { multiplying elements }\end{array}$ & $\begin{array}{l}\text { Number of } \\
\text { layers }\end{array}$ & $\begin{array}{l}\text { Total film } \\
\text { thickness }(\mu \mathrm{m})\end{array}$ & $\begin{array}{l}\text { Nominal PLA } \\
\text { thickness (nm) }\end{array}$ & $\mathrm{X}_{\mathrm{c}}(\%)$ & $\begin{array}{l}\mathrm{X}_{\mathrm{MA}} \\
(\%)\end{array}$ & $\begin{array}{l}\mathrm{X}_{\mathrm{RA}} \\
(\%)\end{array}$ \\
\hline AS & Amorphous system & $\begin{array}{l}\text { Single screw } \\
\text { extrusion }\end{array}$ & $100 / 0$ & 1 & 1 & 300 & 300,000 & 0 & 100 & 0 \\
\hline A3S & $\begin{array}{l}\text { Amorphous } 3 \\
\text {-layer system }\end{array}$ & $\begin{array}{l}\text { Layer multiplying co } \\
\text {-extrusion }\end{array}$ & $25 / 75$ & 0 & 3 & 120 & 30,000 & 0 & 100 & 0 \\
\hline$R 3 S^{a}$ & $\begin{array}{l}\text { Rejuvenated } 3 \\
\text {-layer system }\end{array}$ & $\begin{array}{l}\text { Layer multiplying co } \\
\text {-extrusion }\end{array}$ & $25 / 75$ & 0 & 3 & 120 & 30,000 & 0 & 100 & 0 \\
\hline $\mathrm{C} \mathrm{S}^{\mathrm{b}}$ & $\begin{array}{l}\text { Crystallized } 3 \\
\text {-layer system }\end{array}$ & $\begin{array}{l}\text { Layer multiplying co } \\
\text {-extrusion }\end{array}$ & $25 / 75$ & 0 & 3 & 120 & 30,000 & $28 \pm 2$ & $33 \pm 6$ & $39 \pm 8$ \\
\hline MS & Multilayer system & $\begin{array}{l}\text { Layer multiplying co } \\
\text {-extrusion }\end{array}$ & $25 / 75$ & 8 & 513 & 300 & 300 & 0 & 100 & 0 \\
\hline
\end{tabular}

${ }^{\text {a }}$ Rejuvenated in fast scan DSC by consecutive thermal cycles from 0 to $230^{\circ} \mathrm{C}$.

b Crystallized in press at $85^{\circ} \mathrm{C}$ during three hours.

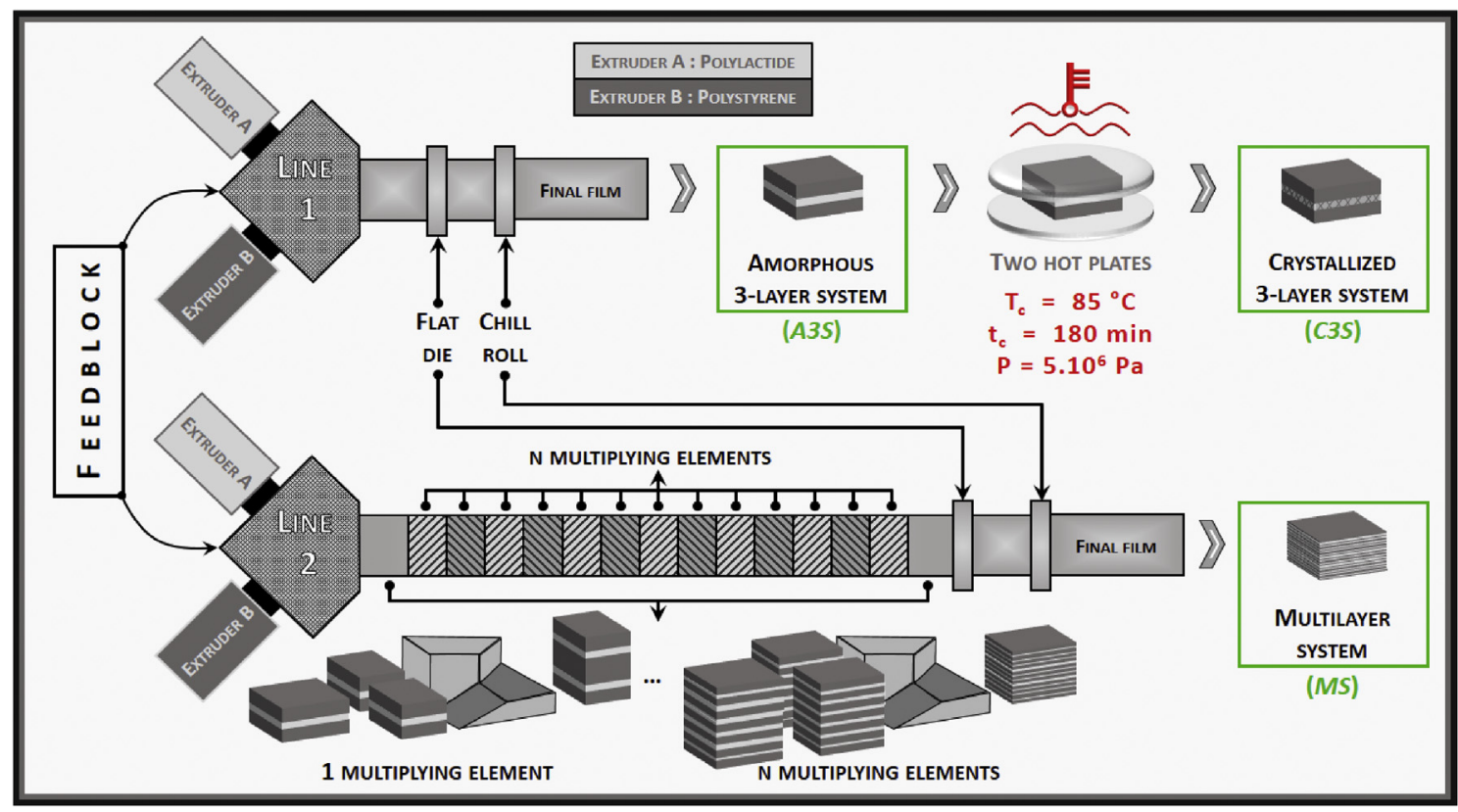

Fig. 1. Principle of the layer multiplying co-extrusion process.

Table 2

The extrusion conditions to fabricate PLA/PS films.

\begin{tabular}{|c|c|c|c|c|}
\hline $\begin{array}{l}\text { PLA extruder temperature profile } \\
\left({ }^{\circ} \mathrm{C}\right)\end{array}$ & $\begin{array}{l}\text { PS extruder temperature profile } \\
\left({ }^{\circ} \mathrm{C}\right)\end{array}$ & $\begin{array}{l}\text { Pump and feed block temperature } \\
\left({ }^{\circ} \mathrm{C}\right)\end{array}$ & $\begin{array}{l}\text { Layer multiplier block temperature } \\
\left({ }^{\circ} \mathrm{C}\right)\end{array}$ & $\begin{array}{l}\text { Flat die temperature } \\
\left({ }^{\circ} \mathrm{C}\right)\end{array}$ \\
\hline $190-200-200-200$ & $200-200-200-210$ & 200 & 200 & 200 \\
\hline Material temperature $\left({ }^{\circ} \mathrm{C}\right)$ & PLA screw speed (rpm) & PS screw speed (rpm) & PLA throughput (g/h) & PS throughput (g/h) \\
\hline 200 & 22 & 57 & 600 & 1800 \\
\hline
\end{tabular}

at $1 \beta_{c} \mathrm{l}=\beta_{h}=1000 \mathrm{~K} \mathrm{~s}^{-1}$ is identical to the value obtained on another sample from the same material by MT-DSC at $\beta_{h}=2 \mathrm{~K} \mathrm{~min}^{-1}$. The mass of the samples typically ranged between 50 and $200 \mathrm{ng}$.

The use of FSC required several steps of calibration for a given heating rate $\left(\beta_{h}=1000 \mathrm{~K} \mathrm{~s}^{-1}\right.$ in the present case). In a first time, the temperature calibration of the sample sensor was performed. To do so, a piece of indium was placed on the reference sensor as schematized in Fig. 2B. This allowed checking the temperature calibration of the sensor. At $\beta_{h}=1000 \mathrm{~K} \mathrm{~s}^{-1}$, an onset melting temperature of $156.6^{\circ} \mathrm{C}$, consistent with the theoretical value, was measured (see Fig. 3A). Then, on the sample sensor, a second piece of indium was disposed on the top of the sample to estimate the static thermal lag $\Delta T_{S}$. This thermal lag was due to the thickness of the sample which creates heat transfer delay and temperature gradients. Its value was estimated from the difference in the onset temperature of both indium melting peaks, as depicted in Fig. 3A, then extrapolated to a theoretical heating rate equal to zero. In addition, the dynamic thermal lag $\Delta T_{D}$ was estimated from a symmetric correction based on the half of the difference in the glass transition temperature measured upon cooling and heating at the same scanning rate $\beta_{h}=\left|\beta_{c}\right|$, using the area matching method 


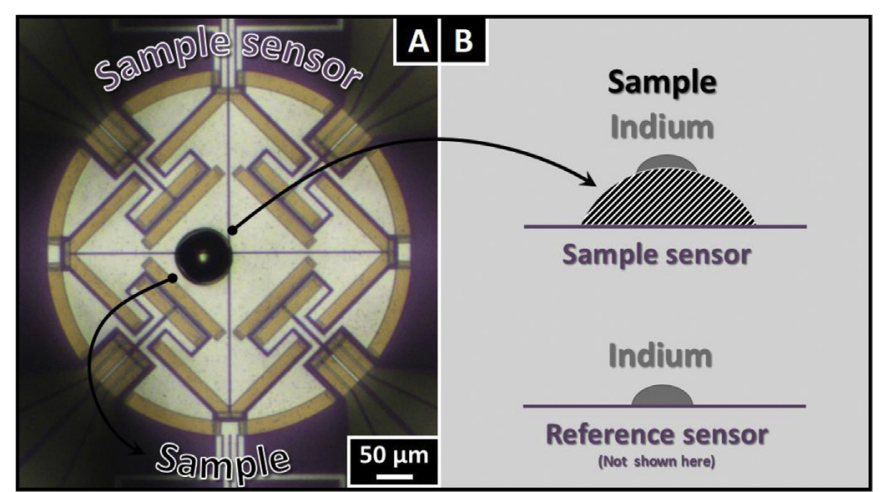

Fig. 2. (A) Photography of the sample sensor. (B) Schematic representation of the positioning of both sample and indium on sample and reference sensors for the determination of the static thermal lag.

proposed by Moynihan et al. [46], as presented in Fig. 3B. The equations giving access to $\Delta T_{S}$ and $\Delta T_{D}$ were proposed by Schawe [47]. As already performed by Monnier et al. [31], and checked in terms of fictive temperature, fragility and physical aging [48], the corrected glass transition temperature of PLA measured upon heating corresponds to the glass transition temperature measured upon cooling, in the case where $\beta_{h}=1000 \mathrm{~K} \mathrm{~s}^{-1}$. By working with only one heating rate of $\beta_{h}=1000 \mathrm{~K} \mathrm{~s}^{-1}$, the glass transition temperature measured upon cooling $T_{g}$ cool from $\boldsymbol{A S}$ was taken as reference in this work to study physical aging.

\subsection{Physical aging}

The aging kinetics was studied by means of FSC and with this respect a methodological question needed to be solved. The rate of the recovery process is not linearly correlated with the aging temperature $T_{a g}$ and typically shows a maximum [49]; it results from a competition between the driving force, i.e. the degree of undercooling, and the macromolecular mobility (higher at lower undercooling). Physical aging studies are generally performed at a fixed distance from $T_{g}$ cool in the vicinity of the maximum rate. This recommendation is difficult to follow when studying constrained systems ( $\boldsymbol{M S}$ and $\mathbf{C 3 S}$ ), for which the glass transition appears very broad in FSC. In that case, the glass transition temperature can hardly be defined and it is more convenient to consider a glass transition domain. Previous work on PLA showed that an aging temperature $T_{a g}$ equal to $50{ }^{\circ} \mathrm{C}$ led to a strong signature of recovery when crossing the glass transition during subsequent heating [31]. By performing aging at $50^{\circ} \mathrm{C}, T_{a g}=T_{g}$ cool $-16^{\circ} \mathrm{C}$ for both $\boldsymbol{A S}$ and A3S. For constrained systems, by considering the uncertainties on the determination of $T_{g}$ cool, it was established that $T_{a g}$ situated for each sample between $T_{g}$ cool $-15^{\circ} \mathrm{C}$ and $T_{g}$ cool $-25^{\circ} \mathrm{C}$. From the methodological point of view, the investigation of the structural dependence of the physical aging was still possible under the condition to ascertain data by considering the role of the aging temperature.

The physical aging experiments were performed with the aging times $t_{a g}$ varying from 0.001 to $100 \mathrm{~min}$. Prior to the annealing, a good thermal contact was ensured by a consecutive heating and cooling at $1000 \mathrm{~K} \mathrm{~s}^{-1}$, up to $125^{\circ} \mathrm{C}$, and down to $-80^{\circ} \mathrm{C}$. Then the sample was heated at $1000 \mathrm{~K} \mathrm{~s}^{-1}$ up to $125^{\circ} \mathrm{C}$, just below the FSC signature of the glass transition of polystyrene to obtain zero-aged PLA, before being cooled down to $T_{a g}=50^{\circ} \mathrm{C}$ at $1000 \mathrm{~K} \mathrm{~s}^{-1}$. Such a procedure allowed preserving the integrity of the layers and consequently the hard confinement of polylactide by polystyrene. The enthalpy of recovery associated to the physical aging of the PLA for the different materials was calculated by integrating the difference between the scans of an aged sample and a sample with a nil aging time as depicted in Supplementary Information in Figure SI.3.

\section{Results and discussion}

\subsection{Physical aging of unconstrained PLA by means of FSC}

Fig. 4A displays FSC normalized heat flow of $\boldsymbol{A} \boldsymbol{S}$ after aging at $50^{\circ} \mathrm{C}$. The endothermic peak related to the enthalpy relaxation of $\boldsymbol{A S}$ was superimposed to the glass transition and shifted to higher temperatures when the aging time increases from $t_{a g}=0.001 \mathrm{~min}$ to $t_{a g}=100 \mathrm{~min}$. This is classically observed in physical aging experiments. $\triangle C p$ did not change with the aging time, suggesting that the sample remained wholly amorphous despite the successive crossings of the glass transition. To compare the behavior of neat PLA ( $\boldsymbol{A S}$ ) with the behavior of PLA in the neighboring of PS, the analysis of the physical aging of the $\boldsymbol{A} 3 \boldsymbol{S}$ was performed. This experiment was complicated by the thickness of the PLA layer in A3S which was close to $30 \mu \mathrm{m}$. Consequently taking a representative sample of the 3-layer system with a mass of a few ng was challenging. Thus, a piece of $\mathbf{A 3 S}$ was selectively cut in an area where both PS and PLA coexisted in the material and a FSC analysis was carried out by heating up to $230^{\circ} \mathrm{C}$ in order to check the
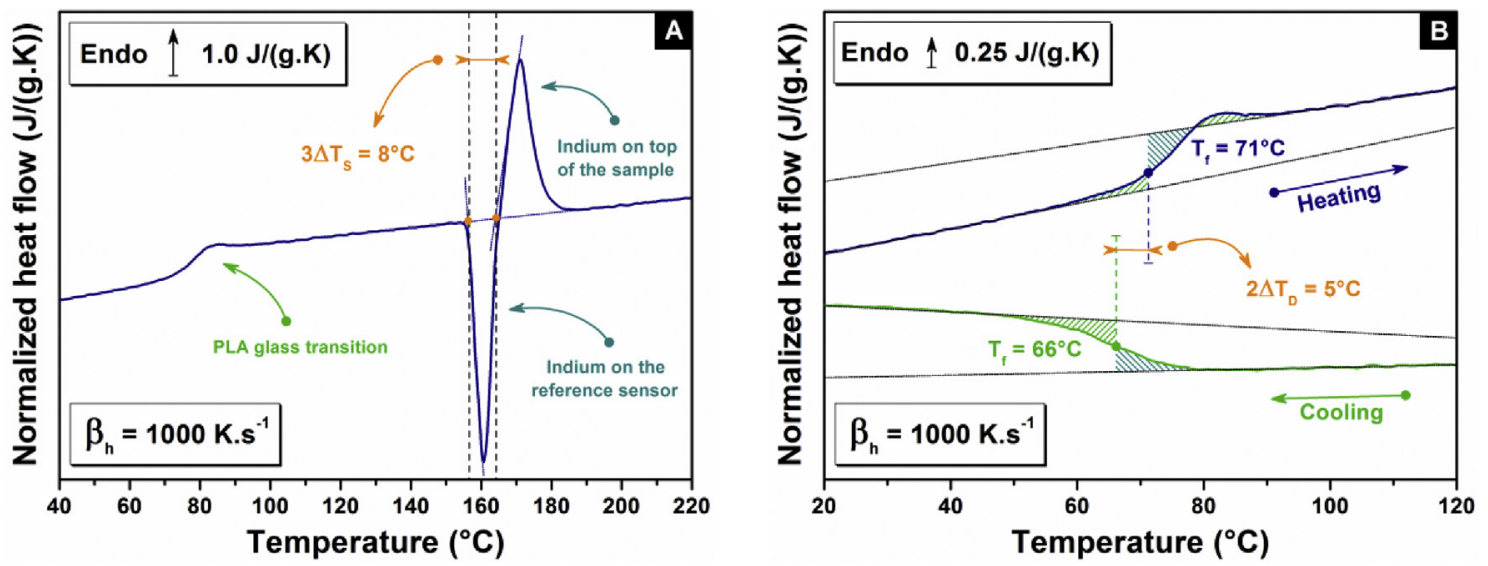

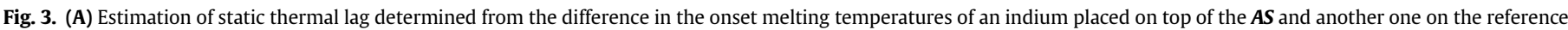

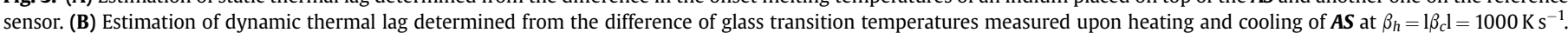



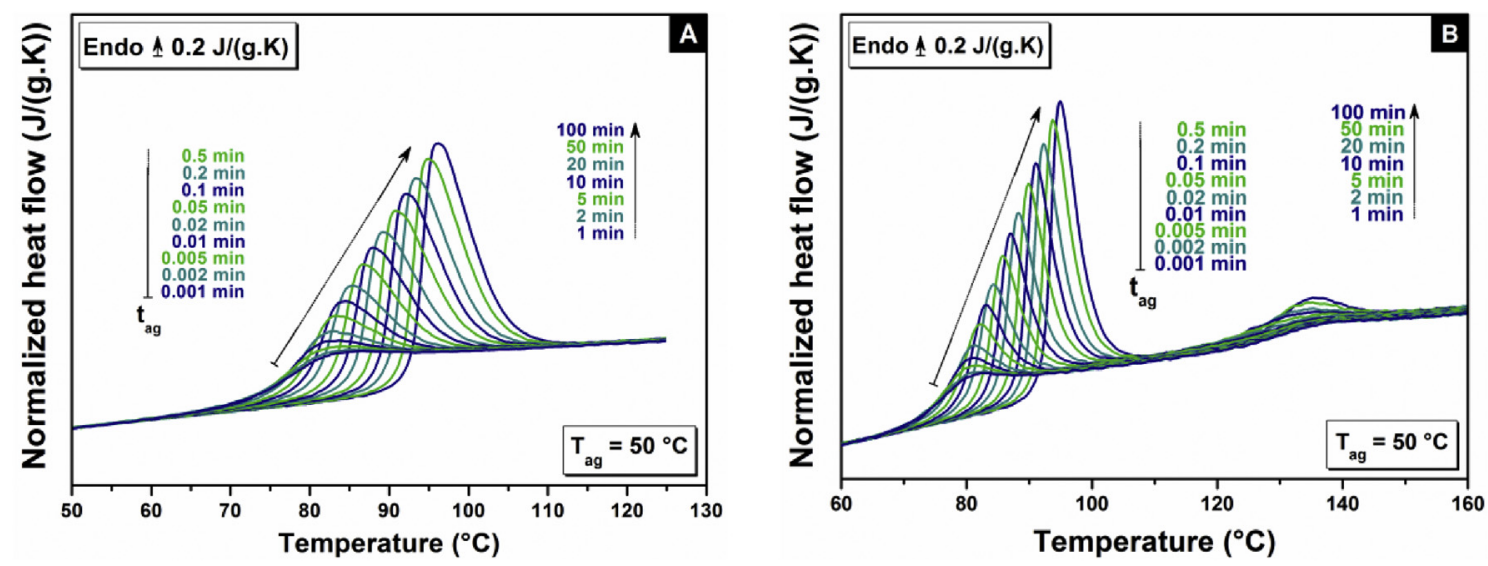

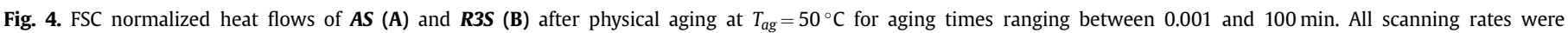
$\beta_{h}=1 \beta_{c} \mathrm{l}=1000 \mathrm{~K} \mathrm{~s}^{-1}$. The sample mass is $m=150 \mathrm{ng}$ for $\boldsymbol{A S}$ and $m=90 \mathrm{ng}$ for $\boldsymbol{R} 3 \boldsymbol{S}$.

presence of the glass transitions of PS and PLA. This procedure caused the rejuvenation of the 3-layer system. The rejuvenated sample (R3S) (Fig. 4B) exhibited an aging behavior similar to $\boldsymbol{A S}$ (Fig. 4A) despite its different thickness. The enthalpy relaxation of PS was of relative low intensity in comparison to PLA. This result might be attributed to a lower content of PS in the cut sample. Besides PS is aged $80^{\circ} \mathrm{C}$ below its glass transition temperature. At larger undercooling (higher $T_{g}-T_{a g}$ ), the rate of densification decreases due to lower molecular mobility, which effects a smaller enthalpy loss within the time-scale of the aging experiment [50].

In Fig. 5, the enthalpy of recovery $\Delta H$ calculated for $\boldsymbol{A S}$ and $\boldsymbol{R} \mathbf{3 S}$ is presented in terms of a structural relaxation function $\varphi\left(t_{a g}\right)=\left(\Delta H_{\infty}\right.$ - $\Delta H) / \Delta H_{\infty}$ where $\Delta H_{\infty}$ is the total enthalpy loss, representing the distance to equilibrium. The structural relaxation function is the same for $\boldsymbol{A S}$ and $\boldsymbol{R} \mathbf{3} \boldsymbol{S}$. The vicinity of PS, like the thickness of the film, did not seem to impact the kinetics of the structural relaxation of amorphous PLA. Fig. 5A shows in addition the structural relaxation function from data reported in previous works [31,51,52] and measured by classical DSC at $T_{g, c o o l}-15^{\circ} \mathrm{C}$, meaning at constant value of total enthalpy loss. The structural relaxation kinetics were much lower than the ones reported from FSC, and the signature of physical aging was detected only after a few minutes aging in DSC, while an increase in the enthalpy of recovery was recorded after a few seconds aging in FSC. This result should find its explanation in the fact that the aging temperature is higher in FSC, leading to shorter relaxation times. The aging rate $R_{a}$, obtained by FSC and classical DSC, was $R_{a}=1.6 \pm 0.1$ and $R_{a}=0.7 \pm 0.1 \mathrm{~J} /$ decade respectively, $R_{a}$ being defined from the enthalpy of recovery variations with aging time (Figure SI.4 in Supplementary Information). $R_{a}$ was already used to compare the physical aging kinetics of various polymer glasses [15,53,54], polymer nanoparticles [55], nanocomposites [40], free-standing films [25,36,56], stacked films [38], co-extruded multilayers [44,57]. In Fig. 5B the structural relaxation function obtained from DSC and FSC are compared for identical temperature of aging $T_{a g}$. Data obtained in the present study at $T_{a g}=50^{\circ} \mathrm{C}$ position well in consistence with the data previously obtained from FSC at $T_{a g}=52,47,44^{\circ} \mathrm{C}$ respectively. It is also observed that, at constant aging temperature, the recovery function obtained from DSC approaches the one obtained from FSC, but the aging still proceeds slower. Since this result does not perfectly follow theoretical predictions assuming that the time to reach equilibrium will be the same, other causes explaining this difference should be considered. A difference of equilibration time when PLA is vitrified in FSC at $0.17 \mathrm{~K} \mathrm{~s}^{-1}$ or $1500 \mathrm{~K} \mathrm{~s}^{-1}$ has been reported previously [31]. Time scale to reach equilibrium has been observed to be longer when PLA is vitrified at lower rate. On the other hand, when the same cooling rate was used in both FSC and DSC, the time needed to reach equilibrium was the same. In FSC the sample is significantly thinner compared to the standard bulk sample analyzed in DSC. Therefore, its surface/volume ratio is higher,
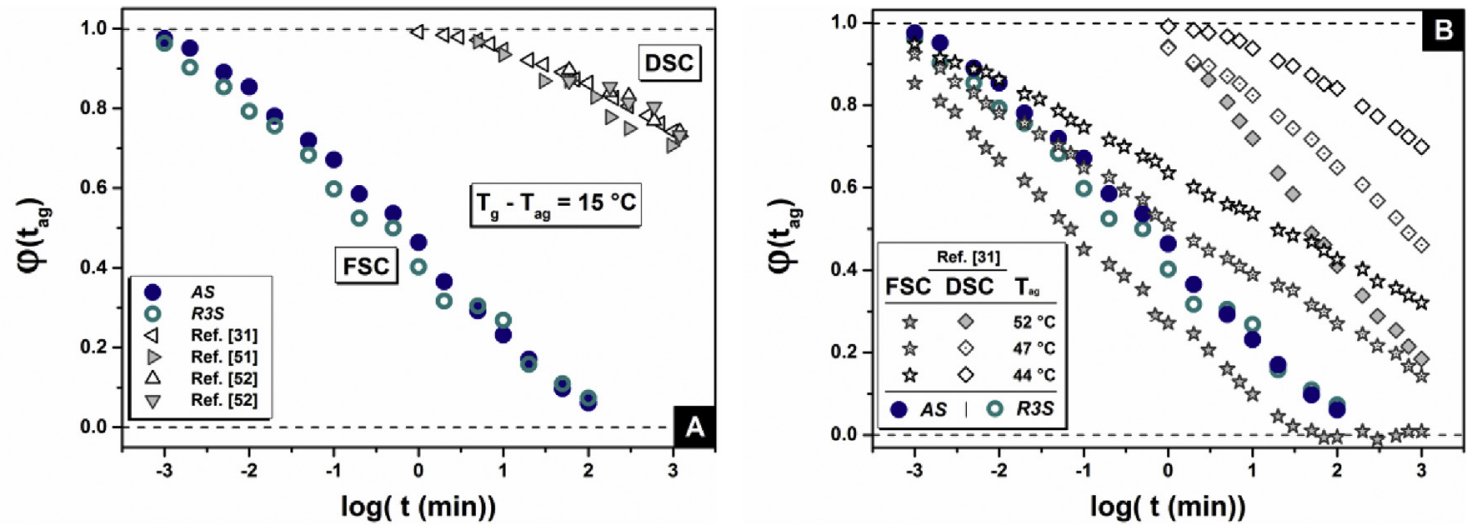

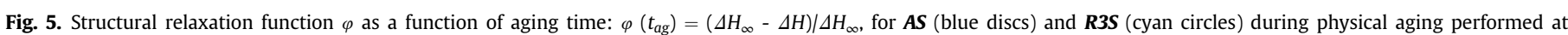

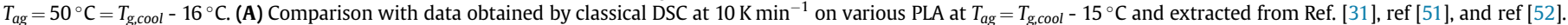

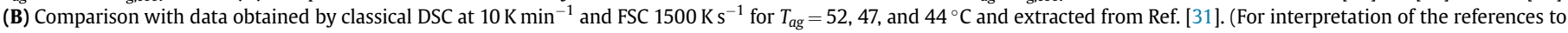
colour in this figure legend, the reader is referred to the Web version of this article.) 
which facilitates the free volume hole diffusion (FVHD) at the free interface. This peculiar property is only observed for high cooling rates. Thus it has been assumed that critical thickness resulting in acceleration of the physical aging was cooling rate dependent. Therefore, from amorphous samples, it is shown that FSC gives more enthalpy recovery and allows investigating physical aging within shorter times at higher temperatures. In the following, benefit of this property has been used to investigate constrained PLA.

\subsection{Physical aging of constrained PLA by means of FSC}

In comparison to $\boldsymbol{A S}$ and $\boldsymbol{R} \mathbf{3 S}$, the glass transition of $\boldsymbol{C} \mathbf{3 S}$ (Fig. 6A) was wider and the enthalpy recovery peak broader. Moreover the peak maximum was situated $15^{\circ} \mathrm{C}$ higher at the longest aging time. The molecular dynamics of the MAF is strongly influenced by the microstructure in semi-crystalline PLA [51]. The amplitude of the heat flow step remained unchanged after the successive passages above the crystallization temperature $\left(T_{c}=85^{\circ} \mathrm{C}\right)$, which showed that the microstructure was not significantly modified. The crystallization of $\boldsymbol{A} \mathbf{3 S}$ (leading to $\mathbf{C} \mathbf{3 S}$ ) decreased the heat capacity step from 0.48 to $0.16 \mathrm{~J} \mathrm{~g}^{-1} \mathrm{~K}^{-1}$, and the MAF only represented $33 \%$ of the quantity material (Table 1 ). The intensity of the endothermic peaks related to physical aging of $\mathbf{C 3 S}$ decreased in consequence. Fig. 6B shows surprisingly that the endothermic peak related to physical aging of the multi-nanolayer sample $\boldsymbol{M S}$, although wholly amorphous, presented the same characteristics as for $\mathbf{C} 3 \mathbf{S}$, i.e. broadened and shifted towards higher temperatures. This behavior has been reported by Poel et al. [58] when positioning the sample too far from the center of the heating area, or when the thermal contact between the sample and the sensor changes during the analysis. In the present study the samples were positioned as close as possible to the center of the sensor like in Fig. $2 \mathrm{~A}$ and oil was used to ensure a good contact with the sensor. Therefore the shift of the glass transition to higher temperatures could result from the constraining of PLA between the layers of polystyrene. Due to the low mass of PLA in MS, the endothermic peak was of weak intensity. The measurement sensitivity was however sufficient to determine the maximum temperature of the recovery peak $T_{\text {peak }}$ and the value of the enthalpy of recovery notwithstanding the signal noise. Fig. 7A plots the increase of $\left(T_{\text {peak }}-T_{g}\right.$ mid $)$ with the aging time. It rose faster in the constrained systems, C3S and $\boldsymbol{M S}$, the effect being more pronounced for $\boldsymbol{M S}$. It is possible that in constrained systems, the local density increase during physical aging induces stronger restrictions of mobility, shifting the recovery process to higher temperatures. It was also observed that the enthalpy recovery values were significantly lower in constrained systems (Fig. 7B). They increased to about $8 \mathrm{~J} / \mathrm{g}$ for $\boldsymbol{A S}$ and $\boldsymbol{R} 3 \boldsymbol{S}$, but only to $2 \mathrm{~J} / \mathrm{g}$ for $\mathbf{C} 3 \boldsymbol{S}$ and to $1 \mathrm{~J} / \mathrm{g}$ for $\boldsymbol{M S}$ (Fig. $7 \mathrm{~B}$ ).

However, the direct comparison of the enthalpy of recovery is insufficient to understand the impact of the processing on the physical aging kinetics. Two criticisms can be formulated: i) due to the difficulty to measure the $T_{g}$ of the constrained systems upon cooling the strict equivalence of the undercooling conditions of all samples cannot be asserted, ii) the quantity of PLA relaxing at the glass transition is lower in constrained samples. The $\boldsymbol{M S}$ included PLA and PS and the C $3 S$ was semi-crystalline. That is why the enthalpy recovery values were rescaled in the following to the quantity of PLA relaxing at the glass transition. By rescaling the enthalpy of recovery to the content relaxing at the PLA glass transition, the total enthalpy loss becomes the same for all materials independently on their microstructure (uncertainties being related to the determination of $T_{g}$ ). Thus it allows comparing the enthalpy of recovery in materials exhibit different relaxing contents. Furthermore the effects of different undercooling degrees were taken into account.

\subsection{Influence of the constraint nature on the physical aging kinetics of $M A F$}

As shown in Fig. 8, the rescaling to the quantity of PLA relaxing at the glass transition leads to an increase of the enthalpy of recovery in $\mathbf{C 3 S}$ and $\boldsymbol{M S}$. It is worth mentioning that the participation of RAF to the structural relaxation in PLA has been discussed by Righetti et al. [50]. To consider both possibilities of the structural relaxation of the only MAF, and of the whole amorphous phase, the two rescaling procedures have been performed for the $\mathbf{C} 3 \mathbf{S}$.

However, the values are still lower than those of $\boldsymbol{A S}$ and $\boldsymbol{R} \mathbf{3 S}$. If the microstructure does not impact the physical aging, all curves in Fig. 8 should be superimposed. One could attribute this difference in terms of structural causes linked to the mobility constraints induced by crystals or layer multiplying co-extrusion process. As mentioned above, this hypothesis is only valid when the physical aging conditions are comparable, which is hardly certifiable due to the uncertainties around the glass transition temperature of constrained systems. Therefore, in addition to the experimental data, a physical aging map is proposed in Fig. 8 as a reference. The values of the enthalpy of recovery were calculated with the help of the physical aging data of amorphous PLA (FSC data) published in our previous work [31]. For each undercooling conditions ( $\Delta T=T_{g}$, cool ${ }^{-}$
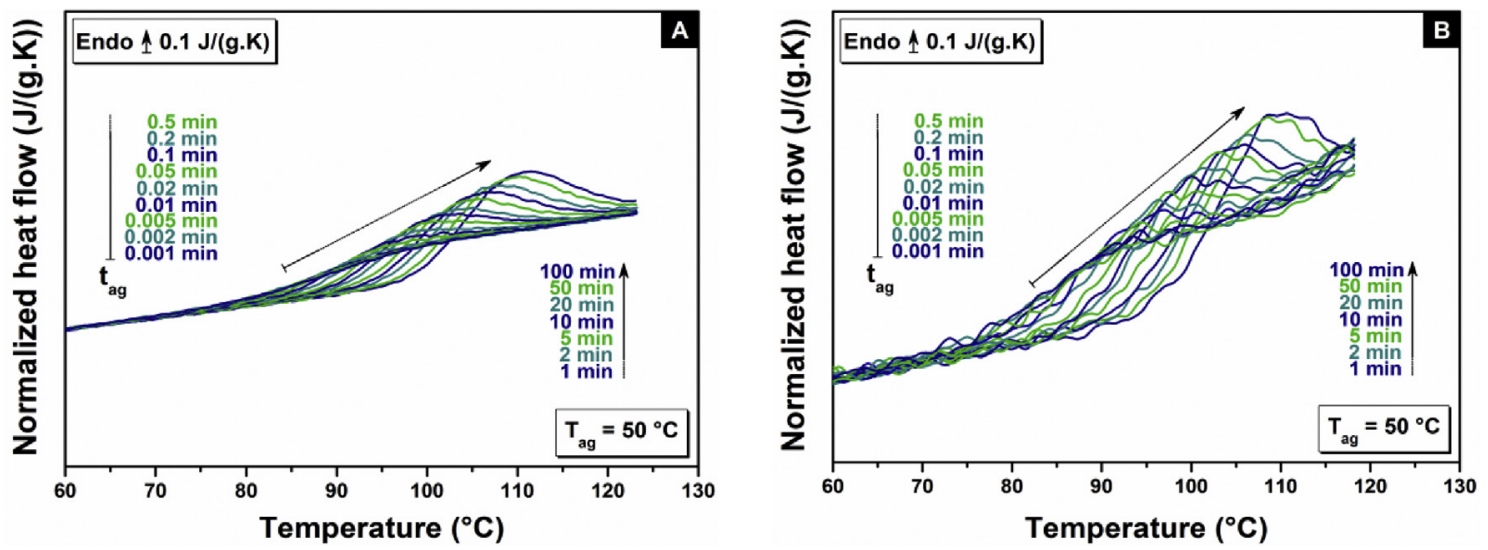

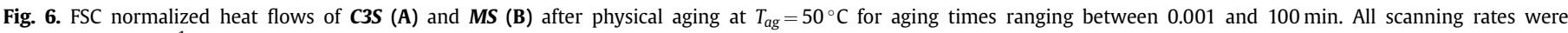
$\beta_{h}=l \beta_{c} l=1000 \mathrm{~K} \mathrm{~s}^{-1}$. The sample mass is $m=170 \mathrm{ng}$ for $\mathbf{C} 3 \boldsymbol{S}$ and $m=60 \mathrm{ng}$ for $\boldsymbol{M S}$ 

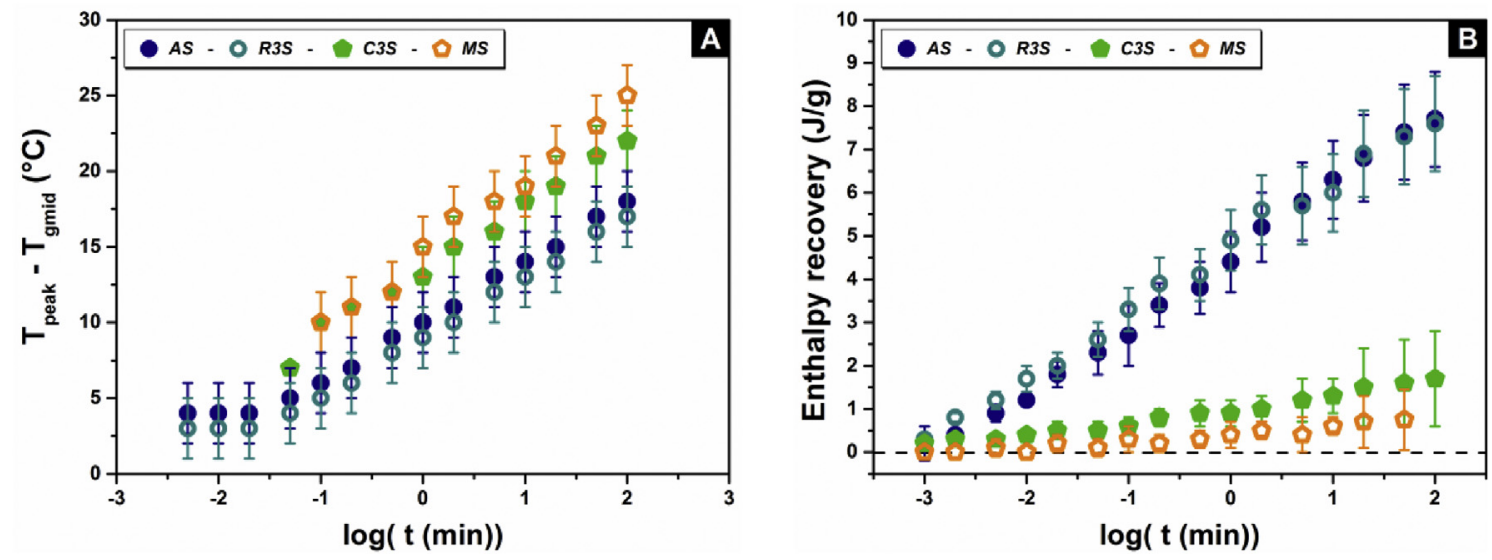

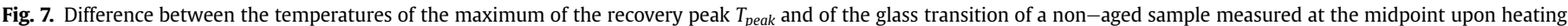

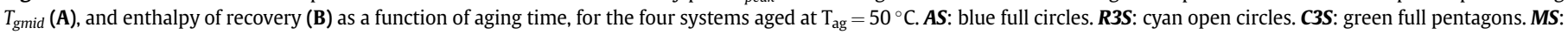
orange empty pentagons. (For interpretation of the references to colour in this figure legend, the reader is referred to the Web version of this article.)

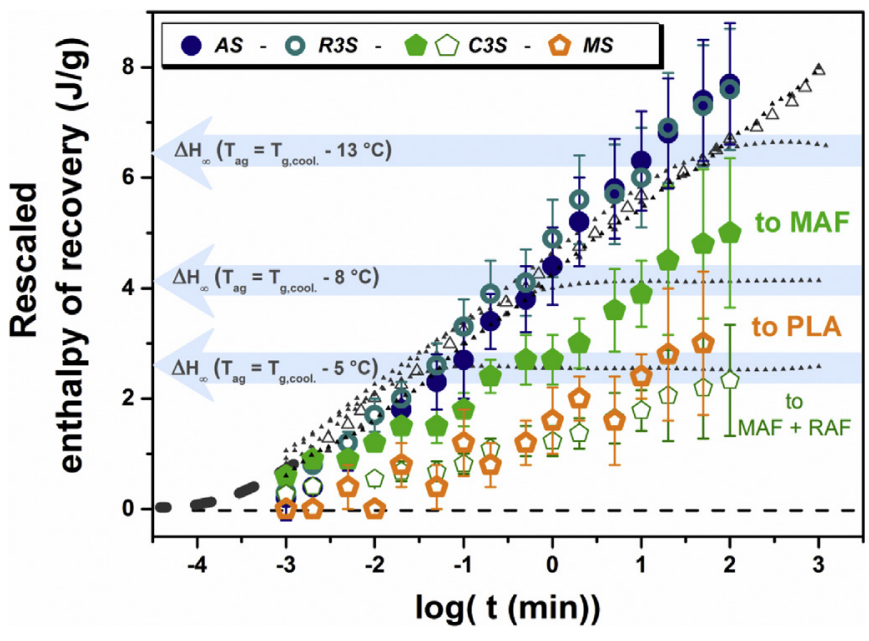

Fig. 8. Time evolution of the enthalpy of recovery rescaled to the content of PLA undergoing structural relaxation, for $\boldsymbol{A S}$ (blue full circles), $\boldsymbol{R} 3 \boldsymbol{S}$ (cyan open circles), $\boldsymbol{M S}$ (orange empty pentagons) C3S assuming the relaxation of MAF alone (green full pentagons), and $\mathbf{C} 3 \mathbf{S}$ assuming the relaxation of the whole amorphous phase (green empty pentagons), during physical aging performed at $50^{\circ} \mathrm{C}$. The physical aging map of a fully amorphous PLA is depicted by adding data obtained from Ref. [31]. The empty triangles correspond to the evolution of enthalpy at $T_{a g}=T_{\text {g.cool }}-23^{\circ} \mathrm{C}$. The small filled triangles correspond to the evolution of enthalpy at $T_{a g}=T_{g, \text { cool }}-18^{\circ} \mathrm{C}, T_{a g}=T_{g, \text { cool }}$ $13^{\circ} \mathrm{C}, T_{\text {ag }}=T_{g, \text { cool }}-8^{\circ} \mathrm{C}$ and $T_{\text {ag }}=T_{g, \text { cool }}-5^{\circ} \mathrm{C}$. For $T_{\text {ag }}=T_{g, \text { cool }}-13^{\circ} \mathrm{C}, T_{\text {ag }}=T_{g, \text { cool }}-8{ }^{\circ} \mathrm{C}$ and $T_{a g}=T_{\text {g.cool }}-5^{\circ} \mathrm{C}$, the blue arrows depict the maximum enthalpy of recovery $\Delta H_{\infty}$, corresponding to the total enthalpy loss when the system reaches the thermodynamic equilibrium extrapolated from the liquid state under physical aging conditions. The grey dashed line aims to guide the eye in the initiation period in the aging kinetic. (For interpretation of the references to colour in this figure legend, the reader is referred to the Web version of this article.)

$\left.T_{a g}\right)$, the total enthalpy loss $\Delta H_{\infty}=\Delta C p^{*}\left(T_{g}\right.$, cool $\left.-T_{a g}\right)$ which increases with the degree of undercooling, and which is related to the necessary change in the enthalpy of recovery to reach the thermodynamic equilibrium, was theoretically estimated. For $\Delta T=\left[5^{\circ} \mathrm{C} ; 8^{\circ} \mathrm{C} ; 13^{\circ} \mathrm{C}\right]$, the total enthalpy loss was experimentally reached, the values equaled to $2.5 \mathrm{~J} / \mathrm{g}, 4.1 \mathrm{~J} / \mathrm{g}, 6.6 \mathrm{~J} / \mathrm{g}$, respectively (they are highlighted by blue arrows in Fig. 8). The thermodynamic equilibrium was not reached at $\Delta T=\left[18^{\circ} \mathrm{C} ; 23^{\circ} \mathrm{C}\right]$ within the experimental aging time.

The reference samples $\boldsymbol{A S}$ and $\boldsymbol{R} \mathbf{3 S}$ exhibited the same recovery kinetics $\left(R_{a}=1.6 \pm 0.1 \mathrm{~J} /\right.$ decade $)$ at all undercooling conditions. This means that the time needed to reach the thermodynamic equilibrium in these aging conditions is only dependent on the total enthalpy loss $\Delta H_{\infty}$. As discussed before, the undercooling conditions ( $\Delta T=T_{g}$, cool $-T_{a g}$ ) of $\mathbf{C} 3 \boldsymbol{S}$ and $\boldsymbol{M S}$ aging could not be precisely controlled due to the measurement uncertainty on their $T_{g}$. It was nevertheless possible to observe modifications in their structural relaxation (Fig. 8). The physical aging kinetics of $\mathbf{C} 3 \boldsymbol{S}$ and $\boldsymbol{M S}$ were clearly delayed compared to $\boldsymbol{A S}$ and $\boldsymbol{R} 3 \boldsymbol{S}$.

The aging rate of $\mathbf{C} 3 \mathrm{~S}$ was $0.6 \pm 0.2 \mathrm{~J} /$ decade when rescaled to the total content of amorphous phase (MAF + RAF) and it was $R_{a}=0.9 \pm 0.1 \mathrm{~J} /$ decade, when rescaled to the MAF content only. The decrease of the physical aging rate with increasing crystallinity degree has been reported for several semi-crystalline polymers, including polypropylene [59], poly (phenylene sulfide) [60], or PEEK [61]. Monnier et al. [62] observed that the structural recovery functions between semi-crystalline PLA crystallized under quiescent or flow-induced conditions were similar, with an aging rate of $1.1 \pm 0.1 \mathrm{~J} /$ decade, if rescaled to the MAF content. These results are consistent with ours.

The aging rate of $\boldsymbol{M S}$ decreased to $0.6 \pm 0.2 \mathrm{~J} /$ decade. This result is consistent with reports on multilayer samples by other authors [44]. Murphy et al. [21] observed that the effect of physical aging in nanolayers obtained by co-extrusion stands in contrast to studies with thin, freestanding films. It can be explained by the presence of capped interfaces in multilayer systems instead of free surface. Indeed, the existence of free surface facilitates the free volume hole diffusion. In these systems, an acceleration of physical aging is typically reported $[63,64]$, that can affect macroscopic properties, permeability for example. Several studies have highlighted that the glass transition of bulk samples does not evolve under confinement when the free surface is suppressed by hard confinement [65], irreversible adsorption [66], and crystallization [67]. Physical aging may also be hindered due to attractive interactions of the polymer with the neighboring surface [68-70] or, using an alternative hypothesis, slowing down of the free volume hole diffusion (FVHD) at the surface [22,71]. It has been observed that the acceleration of physical aging, occurring in thin freestanding films and in stacked films, in terms of the time required to reach equilibrium, associated the depression of the glass transition temperature [30]. Furthermore Fukao et al. [38,72] have shown that the rate of physical aging in stacked films could evolve from thin film like to bulk like with interlayer diffusion. In the multilayer system investigated in the present study, it is interesting to observe that the constraints generate an increase of the glass transition, in contrast to the behavior of stacked films. In addition to that the structural 
relaxation can be impacted by the fabrication process [73], which can, like in the multi-nanolayer coextrusion process, impose high elongation and shear rates on the polymer melt. Ghazaryan et al. [74] reported that both uniaxial and biaxial plastic deformation, in excess of $150 \%$ plastic strain, decelerates, and possibly prohibits the physical aging process. Finally, the thickness of the PLA layer is about $300 \mathrm{~nm}$ in the multilayer system and at this length, the distinction between constraint and confinement is debatable. It has been shown in Ref. [10] that PLA confined at $20 \mathrm{~nm}$ length exhibits significantly different dynamics than $300 \mathrm{~nm}$ PLA layer. Thus, studies relating geometric confinement such as [39] can, not surprisingly, report different behavior.

It is noteworthy that the aging kinetics was slower for $\boldsymbol{M S}$ than for C3S when assuming that only the MAF undergoes physical aging, whereas both C3S and MS curves superimposed when assuming that the total amorphous phases underwent structural relaxation. The samples $\mathbf{C 3 S}$ and $\boldsymbol{M S}$ give thus insight in the importance of geometrical constraints respectively with and without covalent coupling to the adjacent hard phase. The slowing down of the aging kinetic in the $\boldsymbol{M S}$ sample imposed by geometric constraining of the amorphous phase between two hard walls was strong enough to be compared to the mobility constraining resulting from crystallization.

\section{Conclusion and perspectives}

The use of fast scanning calorimetry allows obtaining information about the structural relaxation kinetics in a magnified scale. It is shown here that the layer multiplication co-extrusion process is able to slow down the physical aging in amorphous PLA on a level equivalent or higher than thermal crystallization. This observation is however limited to one PLA layer thickness and it would be interesting to investigate this property in an extended range. The causes explaining the slowing down of the structural relaxation might be multiple, possibly involving the role of capped interfaces and the internal stress linked to confinement and orientation of the macromolecules. The possibility of restricting the structural damages caused by physical aging would be of interest for industrial development of multilayer films.

\section{Appendix A. Supplementary data}

Supplementary data related to this article can be found at https://doi.org/10.1016/j.polymer.2018.07.017.

\section{References}

[1] M. Jamshidian, E.A. Tehrany, M. Imran, M. Jacquot, S. Desobry, Poly-Lactic acid: production, applications, nanocomposites, and release studies, Compr. Rev. Food Sci. F 9 (2010) 552-571.

[2] R. Salazar, S. Domenek, V. Ducruet, Interactions of flavoured oil in-water emulsions with polylactide, Food Chem. 148 (2014) 138-146.

[3] V. Ducruet, S. Domenek, Characteristics and applications of poly(lactic acid), in: S. Kalia, L. Averous (Eds.), Biodegradable and Bio-based Polymers: Environmental and Biomedical Applications, Scrivener Publishing LLC, Beverly MA, 2015, pp. 171-224.

[4] A. Guinault, C. Sollogoub, V. Ducruet, S. Domenek, Impact of crystallinity of poly(lactide) on helium and oxygen barrier properties, Eur. Polym. J. 48 (2012) 779-788.

[5] S. Fernandes-Nassar, A. Guinault, N. Delpouve, V. Divry, V. Ducruet, C. Sollogoub, S. Domenek, Multi-scale analysis of the impact of polylactide morphology on gas barrier properties, Polymer 108 (2017) 163-172.

[6] H. Wang, J.K. Keum, A. Hiltner, E. Baer, Confined crystallization of PEO in nanolayered films impacting structure and oxygen permeability, Macromolecules 42 (2009) 7055-7066.

[7] M. Mackey, L. Flandin, A. Hiltner, E. Baer, Confined crystallization of PVDF and a PVDF-TFE copolymer in nanolayered films, J. Polym. Sci., Polym. Phys. Ed. 49 (2011) 1750-1761.

[8] M. Boufarguine, A. Guinault, G. Miquelard-Garnier, C. Sollogoub, PLA/PHBV films with improved mechanical and gas barrier properties, Macromol. Mater.
Eng. 298 (2013) 1065-1073.

[9] T. Messin, N. Follain, A. Guinault, C. Sollogoub, V. Gaucher, N. Delpouve, S. Marais, Structure and barrier properties of multinanolayered biodegradable PLA/PBSA films: confinement effect via forced assembly coextrusion, ACS Appl. Mater. Interfaces 9 (2017) 29101-29112.

[10] S. Fernandes-Nassar, S. Domenek, A. Guinault, G. Stoclet, N. Delpouve C. Sollogoub, Structural and dynamic heterogeneity in the amorphous phase of poly(L,L-lactide) confined at the nanoscale by the coextrusion process, Macromolecules 51 (2018) 128-136.

[11] A.J. Kovacs, Transition vitreuse dans les polymeres amorphes. Etude phenomenologique, Fortschr. Hochpolym.-Forsch. 3 (1963) 394-507.

[12] L.C.E. Struik, Physical Aging in Amorphous Glassy Polymers and Other Materials, Elsevier Science, Amsterdam, 1978.

[13] G.B. McKenna, Glass formation and glassy behavior, in: C. Booth, C. Price (Eds.), Comprehensive Polymer Science, Vol. 2: polymer propertiesPergamon Press, Oxford, 1989, pp. 311-362.

[14] I.M. Hodge, Enthalpy relaxation and recovery in amorphous materials, J. NonCryst. Solids 169 (1994) 211-266.

[15] J.M. Hutchinson, Physical aging of polymers, Prog. Polym. Sci. 20 (1995) $703-760$.

[16] P. Pan, B. Zhu, Y. Inoue, Enthalpy relaxation and embrittlement of poly(L-lactide) during physical aging, Macromolecules 40 (2007) 9664-9671.

[17] N. Burgos, V.P. Martino, A. Jimenez, Characterization and ageing study of poly(lactic acid) films plasticized with oligomeric lactic acid, Polym. Degrad. Stabil. 98 (2013) 651-658.

[18] V.M. Boucher, D. Cangialosi, A. Alegría, J. Colmenero, Enthalpy recovery of PMMA/silica nanocomposites, Macromolecules 43 (2010) 7594-7603.

[19] V.M. Boucher, D. Cangialosi, A. Alegría, J. Colmenero, Enthalpy recovery of glassy polymers: dramatic deviations from the extrapolated liquidlike behavior, Macromolecules 44 (2011) 8333-8342.

[20] Y. Huang, D.R. Paul, Physical aging of thin glassy polymer films monitored by gas permeability, Polymer 45 (2004) 8377-8393.

[21] T.M. Murphy, D.S. Langhe, M. Ponting, E. Baer, B.D. Freeman, D.R. Paul, Physical aging of layered glassy polymer films via gas permeability tracking, Polymer 52 (2011) 6117-6125.

[22] V.M. Boucher, D. Cangialosi, A. Alegría, J. Colmenero, I. Pastoriza-Santos, L.M. Liz-Marzan, Physical aging of polystyrene/gold nanocomposites and its relation to the calorimetric Tg depression, Soft Matter 7 (2011) 3607-3620.

[23] V.M. Boucher, D. Cangialosi, A. Alegría, J. Colmenero, J. González-Irun, L.M. Liz-Marzan, Accelerated physical aging in PMMA/silica nanocomposites, Soft Matter 6 (2010) 3306-3317.

[24] D. Cangialosi, M. Wübbenhorst, J. Groenewold, E. Mendes, S.J. Picken, Diffusion mechanism for physical aging of polycarbonate far below the glass transition temperature studied by means of dielectric spectroscopy, J. NonCryst. Solids 351 (2005) 2605-2610.

[25] J.E. Pye, C.B. Roth, Physical aging of polymer films quenched and measured free-standing via ellipsometry: controlling stress imparted by thermal expansion mismatch between film and support, Macromolecules 46 (2013) 9455-9463.

[26] D. Cangialosi, M. Wübbenhorst, J. Groenewold, E. Mendes, H. Schut, A. van Veen, S.J. Picken, Physical aging of polycarbonate far below the glass transition temperature: evidence for the diffusion mechanism, Phys. Rev. B 70 (2004) 224213.

[27] E. Lopez, S.L. Simon, Signatures of structural recovery in polystyrene by nanocalorimetry, Macromolecules 49 (2016) 2365-2374.

[28] S. Gao, S.L. Simon, Measurement of the limiting fictive temperature over five decades of cooling and heating rates, Thermochim. Acta 603 (2015) 123-127.

[29] Y.P. Koh, S. Gao, S.L. Simon, Structural recovery of a single polystyrene thin film using Flash DSC at low aging temperatures, Polymer 96 (2016) 182-187.

[30] Y.P. Koh, L. Grassia, S.L. Simon, Structural recovery of a single polystyrene thin film using nanocalorimetry to extend the aging time and temperature range, Thermochim. Acta 603 (2015) 135-141.

[31] X. Monnier, A. Saiter, E. Dargent, Physical aging in PLA through standard DSC and fast scanning calorimetry investigations, Thermochim. Acta 648 (2017) $13-22$.

[32] S.L. Simon, Y.P. Koh, The glass transition and structural recovery using flash DSC, in: C. Schick, V. Mathot (Eds.), Fast Scanning Calorimetry, Springer International Publishing, Switzerland, 2016, pp. 433-459.

[33] D. Cangialosi, V.M. Boucher, A. Alegria, J. Colmenero, Physical aging in polymers and polymer nanocomposites: recent results and open questions, Soft Matter 9 (2013) 8619-8630.

[34] Y. Huang, D.R. Paul, Physical aging of thin glassy polymer films monitored by optical properties, Macromolecules 39 (2006) 1554-1559.

[35] K.D. Dorkenoo, P.H. Pfromm, Accelerated physical aging of thin poly [1-(trimethylsilyl)-1-propyne] films, Macromolecules 33 (2000) 3747-3751.

[36] Y.P. Koh, S.L. Simon, Enthalpy recovery of ultrathin polystyrene film using Flash DSC, Polymer 143 (2018) 40-45.

[37] Y.P. Koh, S.L. Simon, The glass transition and enthalpy recovery of a single polystyrene ultrathin film using Flash DSC, J. Chem. Phys. 146 (2017) 203329.

[38] Y.P. Koh, S.L. Simon, Structural relaxation of stacked ultrathin polystyrene films, J. Polym. Sci., Polym. Phys. Ed. 46 (2008) 2741-2753.

[39] S.L. Simon, J.-Y. Park, G.B. McKenna, Enthalpy recovery of a glass-forming liquid constrained in a nanoporous matrix: negative pressure effects, Eur. Phys. J. E 8 (2002) 209-216. 
[40] H. Lu, S. Nutt, Restricted relaxation in polymer nanocomposites near the glass transition, Macromolecules 36 (2003) 4010-4016.

[41] J.E. Pye, K.A. Rohald, E.A. Baker, C.B. Roth, Physical aging in ultrathin polystyrene films: evidence of a gradient in dynamics at the free surface and its connection to the glass transition temperature reductions, Macromolecules 43 (2010) 8296-8303.

[42] K. Fukao, Glassy and aging dynamics in polymer films investigated by dielectric relaxation spectroscopy, in: C.B. Roth (Ed.), Polymer Glasses, CRC Press, Taylor \& Francis Group, Boca Raton FL, 2016, pp. 243-266.

[43] V.M. Boucher, D. Cangialosi, A. Alegria, J. Colmenero, Enthalpy recovery in nanometer to micrometer thick polystyrene films, Macromolecules 45 (2012) 5296-5306.

[44] D.S. Langhe, T.M. Murphy, A. Shaver, C. LaPorte, B.D. Freeman, D.R. Paul, E. Baer, Structural relaxation of polystyrene in nanolayer confinement, Polymer 53 (2012) 1925-1931.

[45] B. Wunderlich, Reversible crystallization and the rigid-amorphous phase in semicrystalline macromolecules, Prog. Polym. Sci. 28 (2003) 383-450.

[46] C.T. Moynihan, P.B. Macedo, C.J. Montrose, C.J. Montrose, P.K. Gupta M.A. DeBolt, J.F. Dill, B.E. Dom, P.W. Drake, A.J. Easteal, P.B. Elterman, R.P. Moeller, H. Sasabe, J.A. Wilder, Structural relaxation in vitreous materials, Ann. N. Y. Acad. Sci. 279 (1976) 15-35.

[47] J.E.K. Schawe, Measurement of the thermal glass transition of polystyrene in a cooling rate range of more than six decades, Thermochim. Acta 603 (2015) $128-134$.

[48] X. Monnier, A. Saiter, E. Dargent, Vitrification of PLA by fast scanning calorimetry: towards unique glass above critical cooling rate? Thermochim. Acta 658 (2017) 47-54.

[49] S. Montserrat, Physical aging studies in epoxy resins. I. kinetics of the enthalpy relaxation process in a fully cured epoxy resin, J. Polym. Sci., Polym. Phys. Ed. 32 (1994) 509-522.

[50] M.C. Righetti, M. Gazzano, N. Delpouve, A. Saiter, Contribution of the rigid amorphous fraction to physical ageing of semi-crystalline PLLA, Polymer 125 (2017) 241-253.

[51] N. Delpouve, M. Arnoult, A. Saiter, E. Dargent, J.-M. Saiter, Evidence of two mobile amorphous phases in semicrystalline polylactide observed from calorimetric investigations, Polym. Eng. Sci. 54 (2014) 1144-1150.

[52] L. Dobircau, N. Delpouve, R. Herbinet, S. Domenek, L. Le Pluart, L. Delbreilh, V. Ducruet, E. Dargent, Molecular mobility and physical ageing of plasticized poly(lactide), Polym. Eng. Sci. 55 (2015) 858-865.

[53] B. Frieberg, E. Glynos, G. Sakellariou, P.F. Green, Physical aging of star-shaped macromolecules, ACS Macro Lett. 1 (2012) 636-640.

[54] M. Ma, T. Xue, S. Chen, Y. Guo, Y. Chen, H. Liu, Features of structural relaxation in diblock copolymers, Polym. Test. 60 (2017) 1-5.

[55] C. Zhang, Y. Guo, R.D. Priestley, Confined glassy properties of polymer nanoparticles, J. Polym. Sci., Polym. Phys. Ed. 51 (2013) 574-586.

[56] A. Shavit, R.A. Riggleman, Physical aging, the local dynamics of glass-forming polymers under nanoscale confinement, J. Phys. Chem. B 118 (2014) 9096-9103.

[57] T.M. Murphy, D.S. Langhe, M. Ponting, E. Baer, B.D. Freeman, D.R. Paul, Enthalpy recovery and structural relaxation in layered glassy polymer films, Polymer 53 (2012) 4002-4009.

[58] G.V. Poel, D. Istrate, A. Magon, V. Mathot, Performance and calibration of the
Flash DSC 1, a new, MEMS-based fast scanning calorimeter, J. Therm. Anal. Calorim. 110 (2012) 1533-1546.

[59] J.M. Hutchinson, U. Kriesten, Physical aging and enthalpy relaxation in polypropylene, J. Non-Cryst. Solids 172-174 (1994) 592-596.

[60] R.K. Krishnaswamy, J.F. Geibel, B.J. Lewis, Influence of semicrystalline morphology on the physical aging characteristics of poly(phenylene sulfide), Macromolecules 36 (2003) 2907-2914.

[61] J.R. Atkinson, J.N. Hay, M.J. Jenkins, Enthalpic relaxation in semi-crystalline PEEK, Polymer 43 (2002) 731-735.

[62] X. Monnier, L. Chevalier, A. Esposito, L. Fernandez-Ballester, A. Saiter, E. Dargent, Local and segmental motions of the mobile amorphous fraction in semi-crystalline polylactide crystallized under quiescent and flow-induced conditions, Polymer 126 (2017) 141-151.

[63] M. Yavari, T. Le, H. Lin, Physical aging of glassy perfluoropolymers in thin film composite membranes. Part I. Gas transport properties, J. Membr. Sci. 525 (2017) 387-398.

[64] T.M. Murphy, B.D. Freeman, D.R. Paul, Physical aging of polystyrene films tracked by gas permeability, Polymer 54 (2013) 873-880.

[65] C. Zhang, Y. Guo, R.D. Priestley, Glass transition temperature of polymer nanoparticles under soft and hard confinement, Macromolecules 44 (2011) 4001-4006.

[66] N.G. Perez-de-Eulate, M. Sferrazza, D. Cangialosi, S. Napolitano, Irreversible adsorption erases the free surface effect on the $T_{g}$ of supported films of poly(4-tert-butylstyrene), ACS Macro Lett. 6 (2017) 354-358.

[67] B. Zuo, Y. Liu, Y. Liang, D. Kawaguchi, K. Tanaka, X. Wang, Glass transition behavior in thin polymer films covered with a surface crystalline layer, Macromolecules 50 (2017) 2061-2068.

[68] R.D. Priestley, P. Rittigstein, L.J. Broadbelt, K. Fukao, J.M. Torkelson, Evidence for the molecular-scale origin of the suppression of physical ageing in confined polymer: fluorescence and dielectric spectroscopy studies of polymer-silica nanocomposites, J. Phys-Condens. Mat 19 (2007) 205120.

[69] P.M. Rauscher, J.E. Pye, R.R. Baglay, C.B. Roth, Effect of adjacent rubbery layers on the physical aging of glassy polymers, Macromolecules 46 (2013) 9806-9817.

[70] C.B. Roth, K.L. McNerny, W.F. Jager, J.M. Torkelson, Eliminating the enhanced mobility at the free surface of polystyrene: fluorescence studies of the glass transition temperature in thin bilayer films of immiscible polymers, Macromolecules 40 (2007) 2568-2574.

[71] F. Kremer, M. Tress, E.U. Mapesa, Glassy dynamics and glass transition in nanometric layers and films: a silver lining on the horizon, J. Non-Cryst. Solids 407 (2015) 277-283.

[72] K. Fukao, T. Terasawa, K. Nakamura, D. Tahara, Heterogeneous and aging dynamics in single and stacked thin polymer films, in: T. Kanaya (Ed.), Glass Transition, Dynamics and Heterogeneity of Polymer Thin Films, Advances in Polymer Science, vol. 252, Springer, Berlin, Heidelberg, 2013, pp. 65-106.

[73] C.J. Ellison, S.D. Kim, D.B. Hall, J.M. Torkelson, Confinement and processing effects on glass transition temperature and physical aging in ultrathin polymer films: novel fluorescence measurements, Eur. Phys. J. E 8 (2002) $155-166$.

[74] G. Ghazaryan, R. Schaller, K. Feldman, T.A. Tervoort, Rejuvenation of PLLA: effect of plastic deformation and orientation on physical ageing in poly(L-lactic acid) films, J. Polym. Sci., Polym. Phys. Ed. 54 (2016) 2233-2244. 